\section{Explosive reaction}

SIR - Lovins' 1 review "Nuclear weapons and power-reactor plutonium' lacks mention of prior rebuttals to his position 2,3 . Moreover, in following the transition of this article with a widely circulated draft (personal communication, 20 March 1978), one senses a post hoc justification for his testimony at the Windscale nuclear-fuel reprocessing hearings.

The conclusions drawn by Lovins are unsupported by the analysis. He implies that "power reactors are not an implausible but are rather potentially a peculiarly convenient type of large-scale Pu production reactor', If power reactors were such practical sources, nuclear-weapons states would not be operating special-purpose military plutonium production reactors - they would be buying up reactor-grade plutonium for their weapons programmes, instead of storing it in pools. Reactor-grade plutonium is a dangerous substance, able to sustain a nuclear explosion. But Lovins fails to quantify its military value.

For governments that contemplate becoming nuclear-weapons states, the accessibility of plutonium is only one factor: others are the quality of material, the availability of facilities, and the possibility of nuclear-explosive testing. There are numerous disincentives too.

For "amateurs", there are hurdles not mentioned by Lovins. In general, plutonium generated in power reactors is not suited for military applications, and unauthorized access has been severely restricted by physical safeguards. His superficial treatment does not help our common goal of minimizing the propagation of nuclear weapons.

There are some specific technical objections: His introductory paragraphs are not justified by the subsequent analysis. He applies such terms as "unsuitable", "usable", "inferior", and "less than optimal", to power-reactor $\mathrm{Pu}$. He generates a list of "assumptions" that represent selected extremes, later to render them "false". Although he says "We must know exactly what 'less than optimal' [Pu for bomb-making] means", he does not define it. Lovins eventually admits that there is "somewhat greater technical difficulty in using power-reactor $\mathrm{Pu}$ for effective military bombs.'

His "conservative assumption" that arbitrarily high even-isotope content will not affect his arguments has been challenged, although Lovins does not mention the contradiction. On that assumption, Lovins proposes that "Pu discharged from power reactors will. . . have major military potential"'. His Table 2 does not reach high concentrations of the even-plutonium isotopes, thereby preventing the reader from making independent judgements on the efficacy of isotopic denaturing at higher evenisotope concentrations. Independent estimates of dramatic reductions in explosive yield that accompany isotopic dilution ${ }^{3,4}$ are not included in Table 2 .

He categorizes his choice of parameters as "realistic", thereby dismissing the deleterious effects of other forms of denaturing. Lovins claims that my "analysis of weapons physics seems deeply flawed". That is the entire support he gives to the charge. Yet, his own "weapons physics" is sparse, lacking any equations, and sustained mainly with citations from sources which I consider discreditable.

There are many misunderstandings, oversimplifications and omissions in Lovins' treatment of near-critical fissile masses: the difference between reactivity and excess reactivity; the role of synergistic effects; and his inability to distinguish between laboratory and field developments. I have identified and studied eight phenomena that can adversely affect the yield of an explosive configuration: critical mass dilution, metallurgical phase change, radial compression, subcritical multiplication, predetonation, generation time, reactivity limi and surface leakage. Lovins ignores most of them.

The interpretation that "the least favourable moment cannot get any less favourable" for an explosive yield is contradicted by Poisson statistics - a predetonation contour that Lovins notes but fails to apply. His repeated conception that the "'worst case, minimum, 'fizzle' yield is still. 'militarily useful' ", is inconsistent with probability theory.

Examination of the citations taken by Lovins from Wohlstetter and Gilinsky indicates the origin of his circular arguments regarding plutonium denaturing. Of the limited official information generally available, most current reviews depend heavily on R.W. Selden's unpublished conclusions, which are self-contradictory.

It is incorrect to state "categorically that bombs from reactor-grade or deliberately 'denatured' $\mathrm{Pu}$ are less effective, less powerful or less reliable than those made from weaponsgrade $\mathrm{Pu}$ '. On the other hand, using a term from Lovins, it is "disingenuous" to deny that those attributes may be applied to the average properties of denatured plutonium. I estimate that plutonium can be isotopically denatured as effectively as ${ }^{235} \mathrm{U}$ or ${ }^{233} \mathrm{U}$ at a given fissile fraction. All reactor fuels and reactor types pose comparable levels of difficulty regarding weapons application, given corresponding safeguards and fissile fractions. Weaknesses of one or the other should be identified and remedied. However, the relative reactor usability and supply of isotopically denatured plutonium is another matter.

The point that the "marginal time and money required to use civil reactors for military production are orders of magnitude less than those needed for dedicated military facilities," has an element of truth mixed in with carefree terminology. One must differentiate between base power reactors and small research reactors. Research reactors do indeed provide a hedge, a "civilian cover" for some weapons-grade plutonium production; however, power reactors are self-protected and inaccessible under an appropriate safeguards regime.

Institutional and technological safeguards can minimize diversion and proliferation. As our respective nations expand their arsenals of destructive weapons, such misplaced concern only adds to irresolution. One can transcend some of the dispute by noting that international safeguards and a ban on all testing of nuclear weapons are the most prominent and effective steps that should be taken.

A. De Volpi

Argonne National Laboratory, Argonne, Illinois
1. Lovins, A.B. Nature 283, 817-823 (1980); erratum Nature 284, 190 (1980).

2. Power Engng, p.32 (November 1977); Bull. atom. Scient 34, 62. 59 (1978); 35, 50; 57 (1979); Phys. Today p.84, (December 1978); p.83 (July 1979).

3. De Volpi, A. Proliferation, Plutonium, and Policy: Institutional and Technological Impediments to Nuclear Weapons Propagation (Pergamon, Oxford, 1979). 4. Sahin, S. Nature 287, $578(1980)$

\section{Role for ESF?}

SIR - One aspect of its work that the European Science Foundation (ESF) could substantially expand (Nature 20 November 1980 , pages 202,204 ) is the sponsoring of scientific conferences and schools, especially in interdisciplinary areas.

The association of NATO Advanced Study Institutes and NATO Summer Schools with the NATO military pact is a matter of continuing shame to the academic community. Scientific organizations should be pressing the national governments to agree to the ESF taking over NATO's role in conference sponsorship and funding in Europe. The US side could presumably be accommodated via bilateral NSF-ESF arrangements.

Let's end the shameful military link with scholarship forthwith!

M.K. W ALLIS

University College

Cardiff, $U K$

\section{Theories of cancer}

\section{SIR - In reviewing my book The Politics of} Cancer $^{1}$, Peto ${ }^{2}$ charged that one table (Table 6.4) selectively and deliberately omitted data that would otherwise have questioned the conclusion that low dietary doses of saccharin $(0.01$ per cent) are carcinogenic in rats. This statement is incorrectly based on comparison of Table 6.4 with data in an appendix to the report of the Office of Technology Assessment ${ }^{3}$. However, the caption of Table 6.4 clearly states that it is based on another table, prepared by Melvin Reuber for use in the congressional testimony on saccharin by the Health Research Group on 21 March $1977^{4}$. Peto persisted in publishing this serious allegation in spite of two warnings.

Peto also appears unfamiliar with the content of the Office of Technology Assessment's report, which he cites as the basis for his charges on saccharin. This report explicitly discusses Reuber's low-dose data and his conclusion that "the increased incidence of lymphosarcoma of the thorax in rats at the 0.01 per cent . . . are highly significant in the saccharin study",5. Reuber also emphasizes that the carcinogenic effects of saccharin in various studies were not always dose-related.

Contrary to Peto's impressions, inversions in dose-response data are not uncommon in both experimental and epidemiological carcinogenicity studies. Reasons for such inversions include competing risks, heterogeneity in tested populations, and statistical fluctuation, particularly when doseresponse curves are shallow. Peto also fails to recognize that saccharin has produced tumours in experimental animals at low as well as at relatively high doses.

Contrary to Peto's impression that "it is not surprising that so many chemicals (such as saccharin) at such (high) doses can cause cancer in animals", there is an overwhelming consensus in the qualified, independent 